\title{
Multiple Frequency Notched Planar Monopole Antenna for Multi-band Wireless Systems
}

\author{
W.S.Lee, D.Z.Kim,K.J.Kim, K.S.Son,W.G.Lim and J.W.Yu \\ Department of Electrical Engineering, Korea Advanced Institute of Science and Technology (KAIST),
}

373-1 Guseong-Dong, Yuseong-Gu, Teajon, 305-701, Korea, e-mail:drjwyu@ee.kaist.ac.kr

\begin{abstract}
A multiple band-notched planar monopole antenna for multi-band wireless systems is presented. The proposed antenna consists of a wideband planar monopole antenna and the multiple $U$-shape slots, producing bandnotched characteristics. In order to generate two bandnotched characteristics, we propose that three U-shape slots are required. This technique is suitable for creating ultrawideband (UWB) antenna with narrow frequency notches or for creating multi-band antennas.
\end{abstract}

\section{INTRODUCTION}

A variety of techniques have been used to create multiband antennas. A typical multi-band antenna, which is a composite structure of narrow band resonant components, has a great difficulty in design because of the sophisticated structure and extremely sensitive impedance bandwidth. Such an antenna performs the complex process case by case about the required frequency band [1]. Another technique for a multi-band antenna design is to create a wideband antenna that is responsive to multiple bands of interests.

With the advent of ultra-wideband technology, wideband planar monopole antennas have received increased attention [2-4]. These antennas exhibit good impedance matching, stable radiation patterns, and high efficiency over bandwidths suitable for use with wideband system. Due to collocation of the wideband system with frequency bands reserved for narrowband wireless technologies, there is a need in the wideband device to provide filtering in those bands to avoid interference from or causing interference to narrowband devices. In [5-7], it was shown that by etching a particular feature in the interior of the radiating element, a planar monopole can exhibit a single narrow frequency notch band while maintaining wideband performance.

In this paper, we explore the ability to achieve multiple band-notched characteristics in wideband planar monopole. The concept of multiple band-notched antenna system is illustrated in Figure 1. The ability to provide this function in the antenna can significantly relax the requirements imposed upon the filtering electronics within the wireless device. The proposed antenna is fabricated and studied.

\section{ANTENNA DESIGN}

Figure 2 shows the proposed antenna, which consisting of a planar monopole antenna and multiple half wavelength U-shape slots. The planar monopole antenna

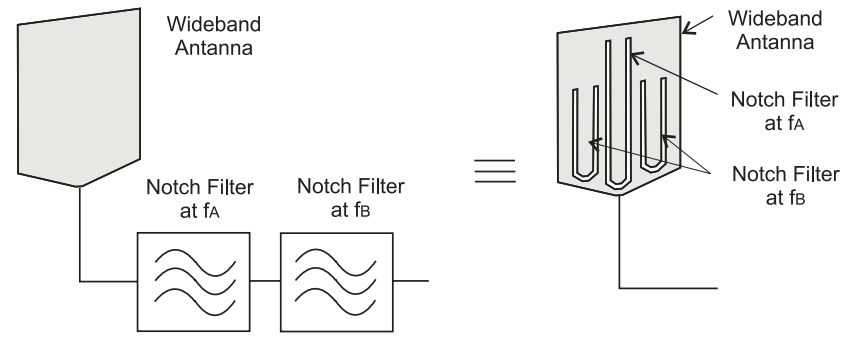

(a)

(b)

Fig. 1. (a) A multi-band antenna system combines a wideband element with notch filters (b) the proposed multiple band-notched antenna system.

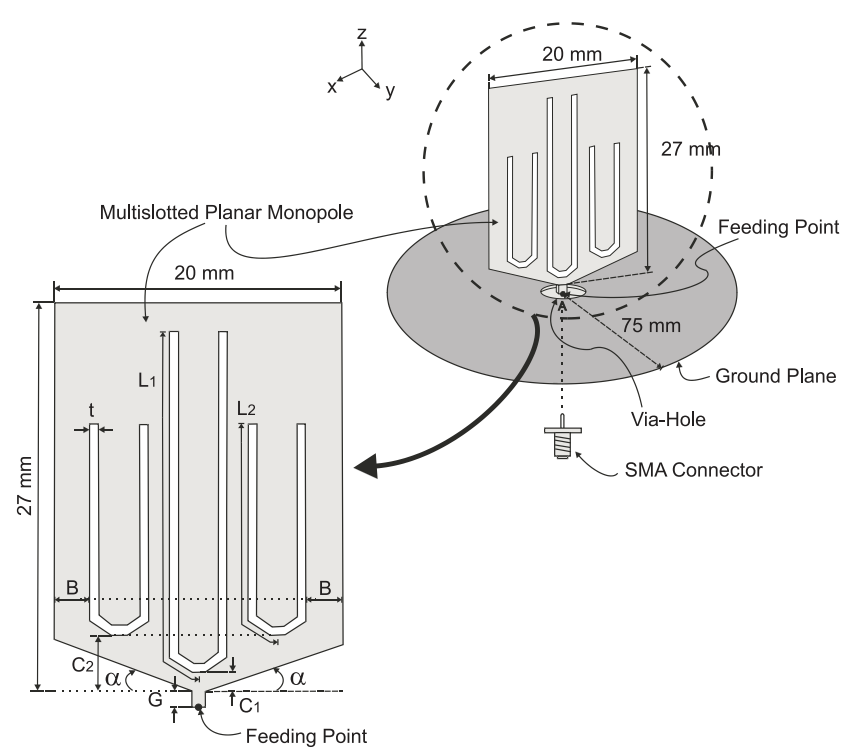

Fig. 2. Geometry of the proposed multiple band-notched planar monopole antenna.

was initially proposed in [2] and further studied in [3] and [4]. There are a number of parameters that influence the bandwidth; these include the size of planar monopole, the feeding gap, the beveling and the size of the ground plane. Prototype antennas were fabricated and mounted on a circular finite ground plane with radius $75 \mathrm{~mm}$. A 50ohms SMA connector, centrally mounted from the back of the ground plane, was used to excite the antenna. A copper planar element of thickness, $0.2 \mathrm{~mm}$, size, $20 \mathrm{x}$ $27 \mathrm{~mm}^{2}$ and beveling angle, $12^{\circ}$, are vertically mounted at spacing $G=1 \mathrm{~mm}$ over the circular ground plane. 


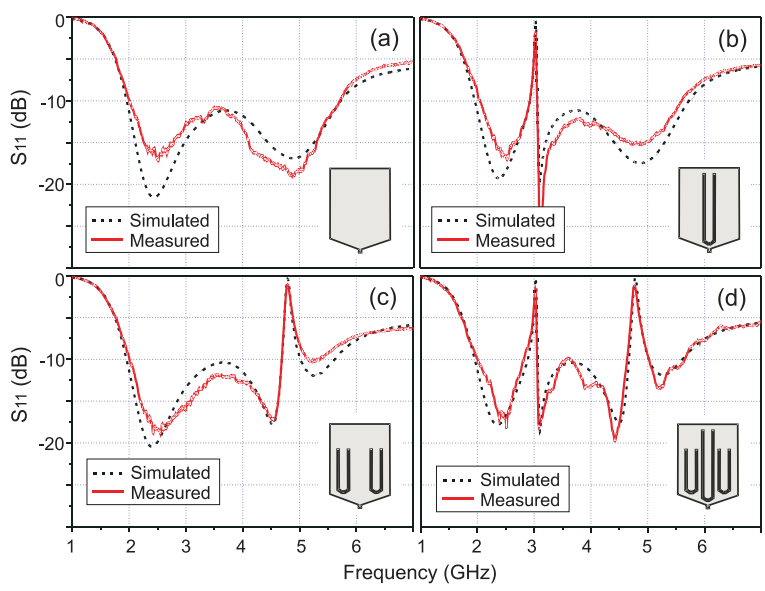

Fig. 3. Measured and simulated return loss versus frequency : (a) without slot (reference antenna), (b),(c) and (d) with slots

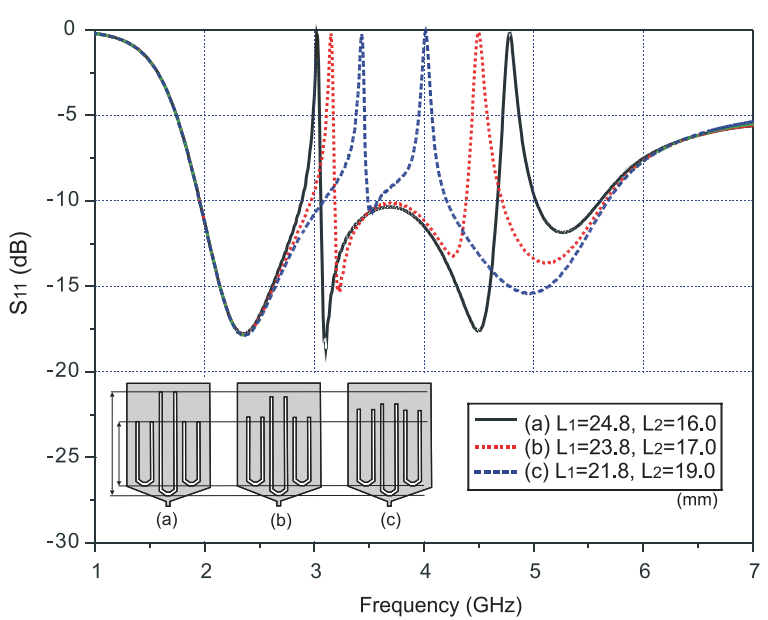

Fig. 4. Return losses for the proposed antenna with various U-shape slot lengths L1 and L2.

To implement the multiple band-notched antenna, the half wavelength U-shape slots are symmetrically inserted in the center of the planar element. Therefore, in order to generate the two band-notched characteristics, we propose that three U-shape slots are required.

\section{EXPERIMENTAL RESULTS}

Figure 3 shows the measured and simulated return loss (S11) for the proposed antenna. The dimensions of the $\mathrm{L} 1, \mathrm{~L} 2, \mathrm{C} 1, \mathrm{C} 2, \mathrm{~B}$ and $\mathrm{t}$ are determined to be $25.0 \mathrm{~mm}$, $16.0 \mathrm{~mm}, 1.0 \mathrm{~mm}, 3.0 \mathrm{~mm}, 2.0 \mathrm{~mm}$ and $0.5 \mathrm{~mm}$ in this study. For the reference antenna, shown in Figure 3 (a), the impedance bandwidth defined by $10 \mathrm{~dB}$ return loss is about $3.7 \mathrm{GHz}$ (from 2.0 to $5.7 \mathrm{GHz}$ ). From the measured return loss, we can observe that the center U-shape slot makes one notch band at $3.03 \mathrm{GHz}$ and the other U-shape slots, which are same and symmetric, make the other notch band at $4.78 \mathrm{GHz}$. Note that the effect of mutual coupling between notch bands is little. The etched feature becomes resonant at the frequency where the length L1(2) is the quarter wavelength.

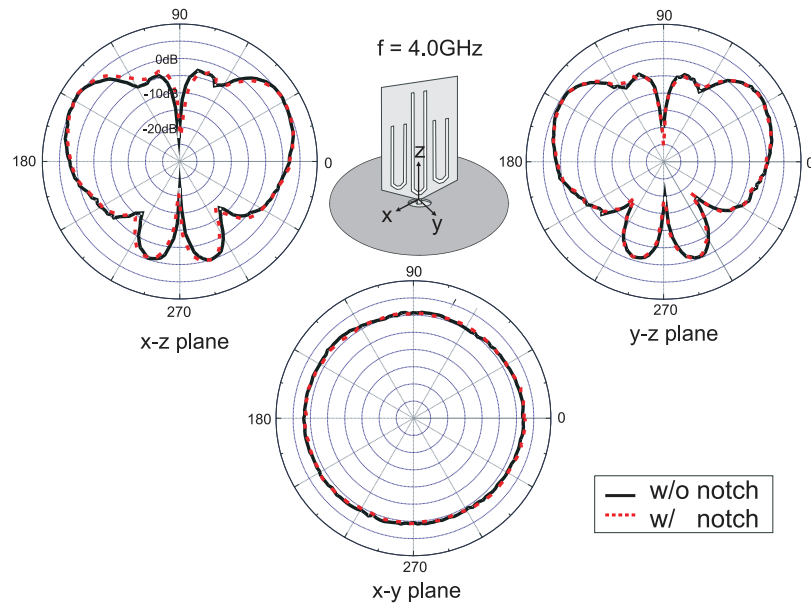

Fig. 5. Measureed radiation patterns at $4.0 \mathrm{GHz}$ passband frequency for the proposed antenna.

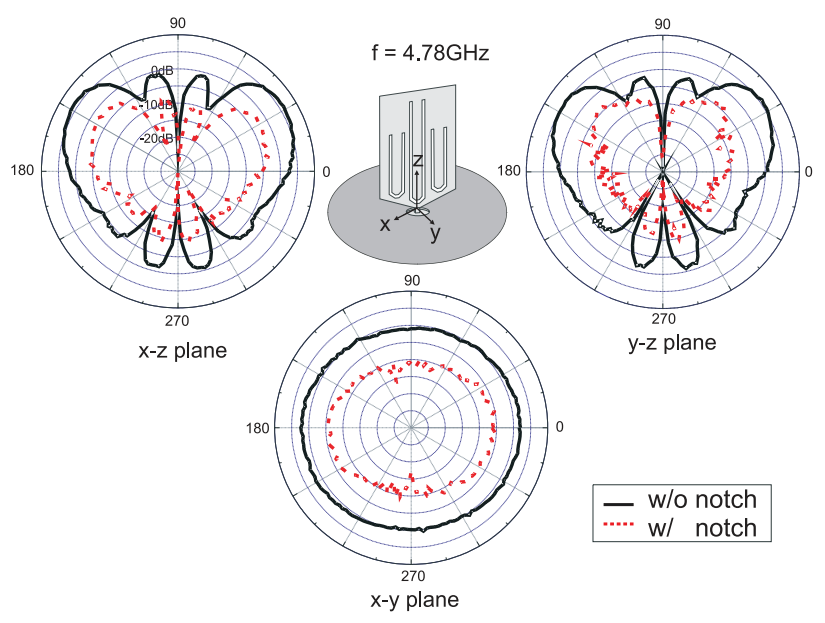

Fig. 6. Measured radiation patterns at $4.78 \mathrm{GHz}$ notch frequency for the proposed antenna.

As described in [7], at the notch frequency, current is concentrated around at the top of the slot and is oppositely directed between the interior and exterior of the slot. This causes the antenna to operate in a transmission line-like mode, which transforms the nearly zero impedance at the top of the slot to high impedance at the antenna feeding point. This high impedance at the feeding point leads to the desired high attenuation and impedance mismatching near the notch frequency. It is also noted that good agreement between the measured data and the simulated results, which are obtained using the CST microwave studio, is observed. Figure 4 shows the simulated results for the proposed antenna with various values of L1 and L2. It can be concluded that the notch bands for the proposed antenna are indeed controlled by the U-shape slots. The radiation patterns of the proposed antenna were also studied. Figures 5 and 6 plot the radiation patterns at $4.0 \mathrm{GHz}$ and $4.78 \mathrm{GHz}$, respectively. The radiation patterns at $4.0 \mathrm{GHz}$ are for the passband frequency. And the radiation patterns at $4.78 \mathrm{GHz}$ are for the notch frequency. 


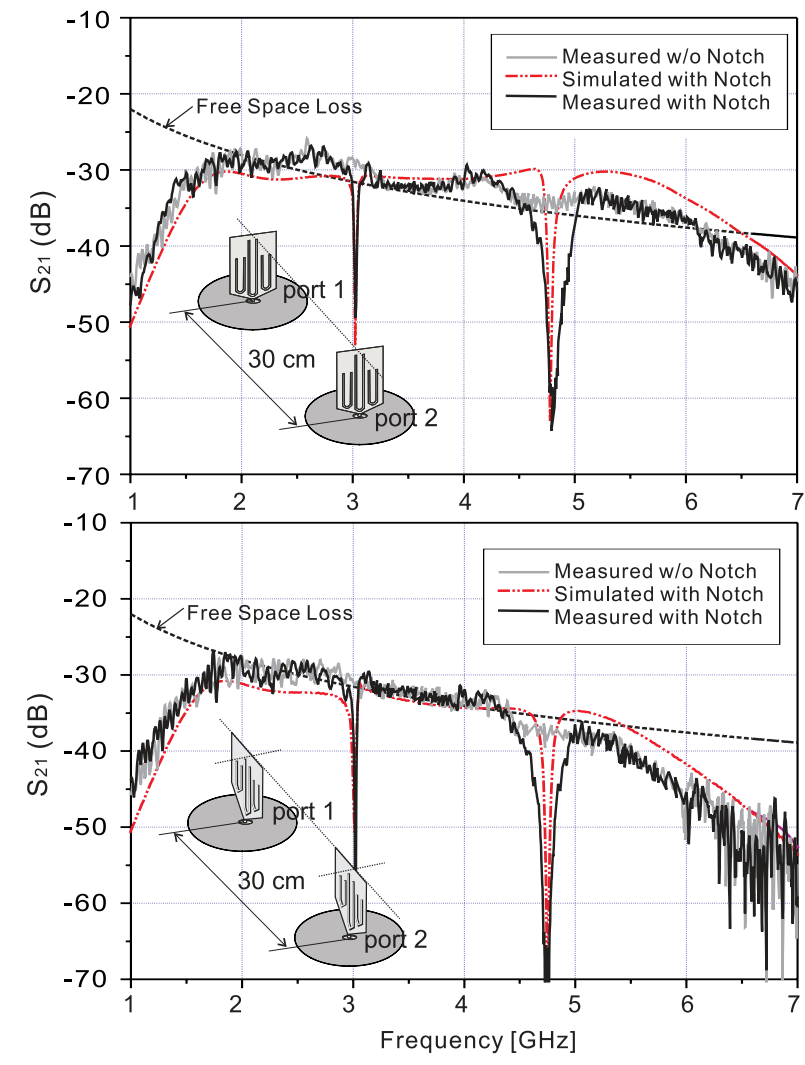

Fig. 7. Measured transmission loss

The radiation patterns at the passband frequency at $4.0 \mathrm{GHz}$ are about the same as those of the reference antenna, that is, the antenna without U-shape slot. In the case of the notch frequency at $4.78 \mathrm{GHz}$, it is noted that the antenna radiation gain reduction due to the U-shape slot is more than approximately $10-15 \mathrm{~dB}$ in the $\mathrm{y}-\mathrm{z}$ plane in the direction of maximum gain. Also, it is noted that the band-notch characteristics are asymmetry in the radiation patterns. Figure 7 shows the measured and simulated transmission loss S21 in the boresight direction $(\theta=0$ in yz plane) and on-edge direction ( $\theta=0$ in $\mathrm{xz}$ plane). The distance between the two antennas is $30 \mathrm{~cm}$. From the measured transmission loss, it can be seen that the relative attenuations $\mathrm{S}_{21 \text { (with notch) }\}} / \mathrm{S}_{21 \text { (ref) }}$ by using two with/without notched antennas are in excess of $20 \mathrm{~dB}$ at the notch bands, and that the attenuation outside of the notch bands is small. For the lower frequencies in the operating band, the antenna gain in general increases with frequency (from about 4 to $6.5 \mathrm{dBi}$ ), while for higher frequencies in the operation band, a stable antenna gain is about $6.5 \mathrm{dBi}$.

\section{CONCLUSION}

In this paper, the multiple band-notched planar monopole antenna has been proposed and a constructed prototype having a wideband operating frequency with two band-notched characteristics at $3.03 \mathrm{GHz}$ and 4.78GHz has been fabricated and tested.

\section{ACKNOWLEDGEMENT}

This work was partially supported by the Brain Korea 21 project and SAMSUNG ELECTRO-MECHANICS Co., Ltd.

\section{REFERENCES}

[1] Yong-Xin Guo, Chia M.Y.W and Zhi Ning Chen, "Miniature built-in multiband antennas for mobile handsets," IEEE Antennas and Propagation Magazine, vol. 52, no. 8, pp. 1936-1944, Aug.2004.

[2] M.J.Ammann, "Square planar monopole antenna," IEE $\mathrm{Na}^{\prime} \mathrm{l}$ Conference on Antennas and Propagation, no.461,April,1999.

[3] M.J.Ammann and Z.N. Chen, Wideband monopole antennas for multiband wireless systems", IEEE Antennas Propagation Magazine, pp.146-150, 2003

[4] Saou-Wen $\sim \mathrm{Su}$, Kin-Lu Wong, Tuan-Tung Cheng and Wen-Shyang Chen, "Finite-Ground-Plane Effects on the Ultra-Wideband Monopole Antenna", Microwave and Optical Technology Letters, vol.43, no.6, pp.535-537, 20 Dec. 2004.

[5] Y. Kim and D.-H. Kwon,"CPW-fed planar ultra wideband antenna having a frequency band notch function",Electronics Letters, vol.40,no.7,April, 2004.

[6] Schantz, H.G., Wolenec, G, and Myszka, E.M.,"Frequency notched uwb antennas", IEEE Conference on Ultra Wideband Systems and Technologies, pp.214-218, Nov. 2003.

[7] Wang-Sang Lee and Jong-Won Yu, "Frequency-notched wideband planar monopole antenna with a L-shape ground plane", Korea Japan Joint Conference-AP/EMC/EMT, pp49-52, Nov 2004. 
